\title{
PROCESSOS CERTIFICADOS EM SISTEMAS AGROINDUSTRIAIS: UM ESTUDO SOBRE A PRODUÇ̃̃O SUSTENTÁVEL DE CAFÉS CERTIFICADOS
}

\author{
Geraldo Magela Jardim Barra"
}

Marcelo Bronzo Ladeira*"

RESUMO: Este trabalho buscou lançar as bases para a construção de um modelo de maturidade para processos certificados em sistema agroindustriais. Para isso, foi desenvolvido um modelo de maturidade para processos certificados no sistema agroindustrial do café por meio de estudo exploratório no segmento de cafés certificados. Após uma pesquisa sobre maturidade de processos e certificações na cafeicultura, o modelo foi desenvolvido com base no código de conduta UTZ Certified (2015) e, em seguida, foi validado por especialistas em gestão de processos, por especialistas em cafeicultura e por cafeicultores. A contribuição deste artigo para o agronegócio está centrada no modelo de maturidade criado e no método do ciclo de maturidade proposto, que permitem identificar os pontos críticos de cada firma individualmente, possibilitando sugerir as recomendações para a melhoria dos processos.

PALAVRAS-CHAVE: Modelos de maturidade em processos; Produção sustentável; Cafés certificados.

\section{CERTIFIED PROCESSES IN AGRO-INDUSTRIAL SYSTEMS: A STUDY ON THE SUSTAINABLE PRODUCTION OF CERTIFIED COFFEE}

ABSTRACT: The bases for the construction of a mature model for certified processes in agro-industrial system are forwarded. A mature model was developed for certified processes within the coffee agro-industrial system by means of an exploratory study in certified coffees. A research on process maturity and certificates in coffee culture was undertaken and a model was developed based on the conduct code UTZ Certified (2015), validated by experts in process management, coffee culture specialists and coffee culture managers. The contribution of current paper for agribusiness is

\footnotetext{
Doutor em Administração pelo CEPEAD/UFMG. Coordenador de Curso de Administração da Rede de Ensino Doctum, Brasil.

** Docente Associado do CEPEAD/UFMG. Doutor em Administração pelo CEPEAD/UFMG e foi Visiting Scholar (pesquisador visitante) da Faculdade de Economia e Comércio da Universidade de Bologna, Itália
} 
centered on the maturity model established and on the proposed maturity cycle method which identifies the critical points of each specific firm. Recommendations for process improvement are thus possible.

KEY WORDS: Process maturing models; Sustainable production; Certified coffee.

\section{INTRODUÇÃO}

As vendas de cafés certificados no mundo cresceu muito desde 2000, definindo um crescente mercado para cafés sustentáveis, no qual o Brasil se destaca como sendo um dos maiores produtores, como demonstrado na safra 2011/2012 (POTTS et al., 2014). De acordo com os dados recentes do Conselho dos Exportadores de Café - CECAFE (2014), estima-se que mais de 8 milhões de sacas de cafés certificados sejam exportadas por ano pelo Brasil.

Dentre os diversos tipos de certificados aceitos no mercado de café, destacase o UTZ Certified, que é um programa de certificação para a produção de café responsável envolvendo o conceito de cadeia de custódia (UTZ CERTIFIED, 2015a), com capacidade para prover um sistema de coordenação do Sistema Agroindustrial SAG do café (LEME, 2015). Importante o destaque de que os produtores brasileiros respondem de $35 \%$ a $40 \%$ do total de 4 milhões de sacas de café UTZ comercializado no mundo (UTZ CERTIFIED, 2015b).

A certificação tem sido um vetor fundamental na promoção do desenvolvimento de melhores práticas de gestão dos processos das firmas envolvidas na produção e comercialização de café no Brasil. Logo, a possibilidade de desenvolvimento de um modelo de maturidade em processos certificados no setor é uma iniciativa relevante de implantação da gestão de processos em grupos estratégicos nos sistemas agroindustriais, como associações e cooperativas.

É mister destacar que o campo de estudos de modelos de maturidade de processos tem recebido um crescente interesse entre acadêmicos e profissionais, tendo aplicação em diversas áreas do conhecimento, como processos organizacionais (HAMMER, 2007), processos em cadeias de suprimentos (MCCORMACK et al., 2003; LOCKAMY; MCCORMACK, 2004; MCCORMACK et al., 2008; OLIVEIRA, 2009), entre 
outros.

Em face do exposto, o objetivo deste artigo é apresentar o desenvolvimento teórico e conceitual de um modelo de maturidade para processos certificados no SAG de café, de forma a subsidiar, em trabalhos empíricos futuros, a investigação das associações entre maturidade dos processos de firmas certificadas e o desempenho mercadológico e financeiro dessas organizações.

O modelo de maturidade proposto neste artigo permite identificar os pontos críticos de cada firma individualmente, possibilitando sugerir as recomendações para a melhoria dos processos, permitindo a priorização de esforços e recursos pela firma. Este trabalho é importante pelo fato do Brasil ser o maior produtor e o maior exportador de café do mundo, totalizando 45,3 milhões de sacas vendidas e 36,7 milhões de sacas exportadas em 2014 (INFORME ESTATÍSTICO DO CAFÉ, 2015).

Este artigo está organizado em cinco partes. Após esta seção de introdução, tem-se a apresentação da metodologia, detalhando a construção do modelo de maturidade e a elaboração do estudo exploratório. Em seguida, o desenvolvimento e validação do modelo de maturidade são apresentados visando a condução de futuras pesquisas sobre o tema. Por fim, são apresentadas as considerações finais.

\section{METODOLOGIA}

Este trabalho pode ser caracterizado como sendo de natureza exploratória, que por meio de uma pesquisa bibliográfica, análise documental, entrevistas e uma seção de grupo focal foi construído o modelo de maturidade.

Inicialmente, visando a construção do modelo de maturidade, foi realizada uma pesquisa bibliográfica sobre os modelos de maturidade durante os anos de 2013 e 2014. Em seguida, foi realizada uma análise documental, a partir do código de conduta da UTZ Certified (2015a) para definição dos construtos do modelo de maturidade. Os atributos dos construtos foram então distribuídos em diferentes níveis de maturidade, seguindo-se aqui os níveis afins ao Modelo de Maturidade para Processos Certificados em SAG. Em sentido convergente à UTZ Certified, foram desenvolvidas as escalas de atributos necessárias ao desenvolvimento de um modelo 
de maturidade, seguindo as orientações de Churchil (1979).

Após a definição dos estágios de maturidade do modelo e a construção das escalas durante o ano de 2014, o modelo e o questionário foram avaliados durante os sete primeiros meses de 2015 por uma equipe de três especialistas em gestão de processos e três especialistas em cafeicultura. Após esta fase, foram apresentados aos entrevistados 1 e 2 em uma reunião na Associação X, e posteriormente ao entrevistado 3, em outra reunião. Em seguida, uma seção de grupo focal foi composta por três produtores e um coordenador de certificação para análise do modelo e do questionário. O Quadro 1 apresenta a relação dos participantes desta pesquisa.

Quadro 1. Relação dos participantes da fase exploratória

\begin{tabular}{|l|l|l|}
\hline Especialista & Cargo & Especialidade \\
\hline Especialista 1 & Professor Doutor & Processos \\
\hline Especialista 2 & Professor Doutor & Processos \\
\hline Especialista 3 & Professor Doutor & Processos \\
\hline Especialista 4 & Pesquisador Doutor & Cafeicultura \\
\hline Especialista 5 & Professor Doutor & Cafeicultura \\
\hline Especialista 6 & Professora Doutora & Cafeicultura \\
\hline Entrevistado 1 & Superintendente da associação X & Cafeicultura \\
\hline Entrevistado 2 & Funcionária da associação X & Cafeicultura \\
\hline Entrevistado 3 & Coordenador de Certificação da associação X & Cafeicultura \\
\hline Participante do Grupo Focal 1 & Produtor membro da associação X & Cafeicultura \\
\hline Participante do Grupo Focal 2 & Produtor membro da associação X & Cafeicultura \\
\hline Participante do Grupo Focal 3 & Produtor membro da associação X & Cafeicultura \\
\hline Participante do Grupo Focal 4 & Coordenador de Certificação da associação X & Cafeicultura \\
\hline
\end{tabular}

onte: Elaborado pelo autor.

\section{RESULTADO E DISCUSSÕES}




\subsection{MODELO DE MATURIDADE}

O modelo de maturidade deste trabalho avalia a maturidade dos processos certificados das firmas por meio de seis atributos. Estes atributos foram distribuídos em cinco níveis de maturidade baseando-se no método de evolução de processos do modelo de maturidade de McCormack et al. (2003). O Quadro 2 demonstra como a maturidade dos processos certificados de cada firma será mensurada. Para cada um dos seis atributos, em cada um dos cinco níveis de maturidade, foram selecionados cinco indicadores que possibilitam definir o escore de maturidade. Cada atributo foi constituído por cinco indicadores mensurados por meio de questões elaboradas em uma escala de cinco pontos, variando de 1 até 5 pontos (Estendido-5 pontos, Integrado-4 pontos, Conectado-3 pontos, Definido-2 pontos, Adhoc-1 ponto). O escore final de cada firma é calculado pelo somatório dos escores obtidos dos cinco indicadores dos seis construtos ponderados pelos níveis de maturidade. A classificação da maturidade da firma será definida pelo somatório de todos os indicadores, utilizando a mediana como ponto chave de transição. Sendo assim, ao apresentar um escore igual ou menor à mediana entre dois níveis de maturidade, a firma ficará classificada no nível inferior de maturidade destes níveis. Ao apresentar um escore maior à mediana entre dois níveis de maturidade, a firma ficará classificada no nível superior de maturidade destes níveis. 
Quadro 2. Modelo de Maturidade

\begin{tabular}{|c|c|c|c|c|c|c|}
\hline 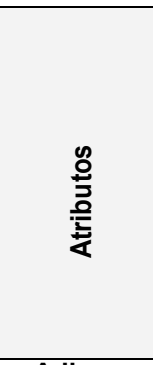 & 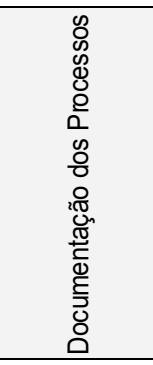 & 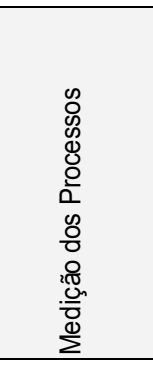 & 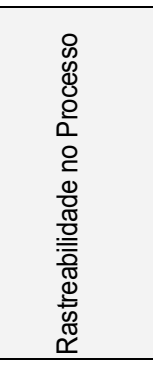 & 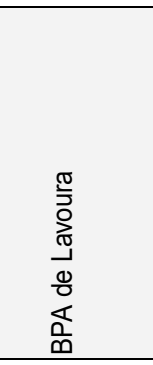 & 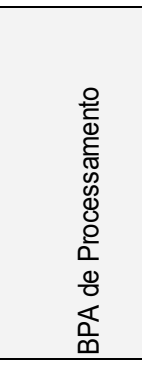 & 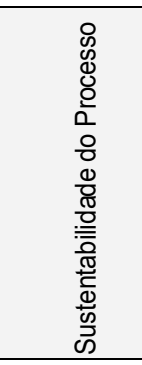 \\
\hline \multicolumn{7}{|l|}{ Adhoc } \\
\hline \multicolumn{7}{|l|}{ Definido } \\
\hline \multicolumn{7}{|l|}{ Conectado } \\
\hline \multicolumn{7}{|l|}{ Integrado } \\
\hline \multicolumn{7}{|l|}{ Estendido } \\
\hline Indicadores & $\begin{array}{l}\mathrm{I}_{01}-\mathrm{I}_{02}-\mathrm{I}_{03}- \\
\mathrm{I}_{04}-\mathrm{I}_{05}\end{array}$ & $\begin{array}{c}\mathrm{I}_{06}-\mathrm{I}_{07}-\mathrm{I}_{08}- \\
\mathrm{I}_{09}-\mathrm{I}_{10}\end{array}$ & $\begin{array}{c}\mathrm{I}_{11}-\mathrm{I}_{12}-\mathrm{I}_{13}- \\
\mathrm{I}_{14}-\mathrm{I}_{15}\end{array}$ & $\begin{array}{c}\mathrm{I}_{16-}-\mathrm{I}_{17-} \mathrm{I}_{18} \\
\mathrm{I}_{19-} \mathrm{I}_{20}\end{array}$ & $\begin{array}{c}I_{21-} I_{22}-I_{23}- \\
I_{24}-I_{25}\end{array}$ & $\begin{array}{c}I_{26}-I_{27}-I_{28}- \\
I_{29}-I_{30}\end{array}$ \\
\hline
\end{tabular}

Fonte: Elaborado pelos autores.

O atributo 1 "Documentação dos Processos" foi definido pelo estágio do sistema de gestão. No atributo 2 "Medição dos Processos" é verificado em que medida o desempenho dos processos é mensurado. O atributo 3 "Rastreabilidade no Processo" identifica em que estágio os produtos são rastreáveis ao longo da cadeia de suprimentos. O atributo 4 "Boas Práticas Agrícolas (BPA) do Processo de Lavoura" verifica em que medida a aplicação de Boas Práticas Agrícolas no processo de lavoura é realizada e efetivada. No atributo 5 "BPA do Processo de Processamento" é verificado em que medida a aplicação de Boas Práticas Agrícolas no processo de processamento é realizada e efetivada. Pelo atributo 6 "Sustentabilidade do Processo" é possível verificar as práticas de sustentabilidade.

A relação entre maturidade e desempenho está presente em diversos modelos de maturidade (LOCKAMY; MCCORMACK, 2004; OLIVEIRA, 2009; BRONZO et al., 2012). De acordo com Lockamy e Mccormack (2004), a literatura sobre orientação para processos de negócios sugere que as organizações podem maximizar seu desempenho global por adotar uma visão organizacional por 
processos. Para Oliveira (2009), um nível alto de maturidade de processos resulta em melhor controle sobre os resultados, previsibilidade em relação aos objetivos de custo e desempenho, efetividade no alcance das metas e na capacidade da gerência propor metas de desempenho superiores.

Coerente com esta posição, a hipótese central deste trabalho é a de que o nível de maturidade dos processos das empresas certificadas está positiva e fortemente associado ao desempenho financeiro e mercadológico dessas organizações. Acredita-se que há uma correlação positiva e relevante entre níveis de maturidade e o desempenho mercadológico e financeiro das empresas certificadas. A Figura 1 sumariza as hipóteses do modelo.

H1: As empresas com processos certificados e que estão posicionadas nos níveis superiores de maturidade apresentam um melhor desempenho mercadológico comparativamente às empresas com níveis inferiores de maturidade.

H2: As empresas com processos certificados e que estão posicionadas nos níveis superiores de maturidade apresentam um melhor desempenho financeiro comparativamente às empresas com níveis inferiores de maturidade.

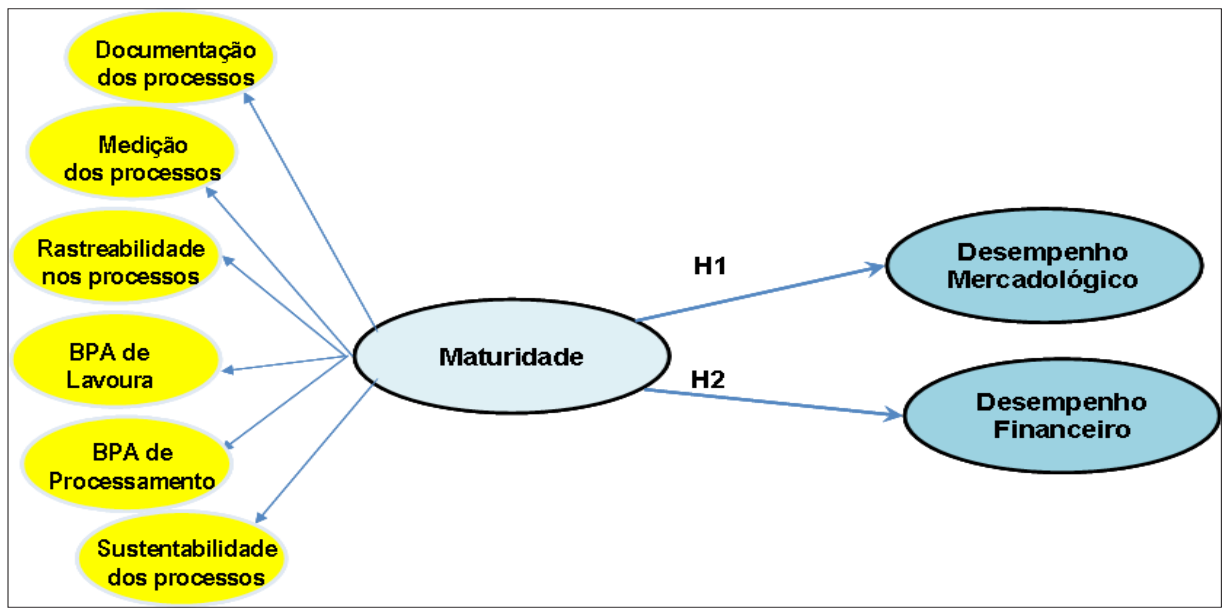

Figura 1. Modelo hipotético-conceitual.

Fonte: Elaborado pelos autores. 
Conforme a Figura 1, entende-se que o construto de segunda ordem "Maturidade" tem natureza reflexiva, sendo constituído pelos construtos de primeira ordem "Documentação do Processo", "Medição dos Processos", "Rastreabilidade no Processo", "BPA do Processo de Lavoura", "BPA do Processo de Processamento" e "Sustentabilidade dos Processos" compilados de Bronzo et al. (2012) e UTZ Certified (2015a). Já os construtos "Desempenho Financeiro" e "Desempenho Mercadológico" assumem um caráter endógeno no modelo, recebendo influência direta do construto "Maturidade". Estes construtos assumem no modelo uma natureza reflexiva. As dimensões destes construtos foram compiladas do trabalho de Bronzo et al. (2012).

\subsubsection{Domínio e Operacionalização dos Construtos}

A concepção da maturidade de processos é a de que o amadurecimento dos processos de negócios perpassa níveis de evolução (LAHTI et al., 2009), que representam capacidades que as empresas possuem relacionadas à padronização, à medição, ao controle e à melhoria contínua de seus processos de negócios. Os processos possuem ciclos de vida, nos quais podem ser definidos, medidos e controlados, e podem ser então gerenciados, em direção à melhoria contínua (MCCORMACK et al., 2009; MCCORMACK et al., 2008; LOCKAMY; MCCORMACK, 2004a). O Quadro 3 apresenta a especificação do domínio do construto "Maturidade de Processos" e a Figura 2 apresenta o ciclo de maturidade.

Quadro 3. Especificação do domínio do construto "Maturidade de Processos"

\begin{tabular}{|c|c|}
\hline \multicolumn{2}{|c|}{ Maturidade de Processos } \\
\hline \multicolumn{2}{|c|}{$\begin{array}{l}\text { São estágios de desenvolvimento, que podem ser explicitamente definidos, medidos, controlados } \\
\text { e gerenciados ao longo do tempo, permitindo refletir em melhoramento do desempenho (LOCK- } \\
\text { AMY; MCCORMACK, 2004). }\end{array}$} \\
\hline Dimensão & Definição \\
\hline Definidos & Processos estão definidos, documentados e compreendidos na empresa \\
\hline Medidos & Processos são medidos na empresa com intuito de controle \\
\hline Controlados & Processos são controlados com intuito de gerenciá-los \\
\hline Gerenciados & Processos são geridos com intuito estratégico \\
\hline
\end{tabular}

Fonte: Elaborado pelos autores. 


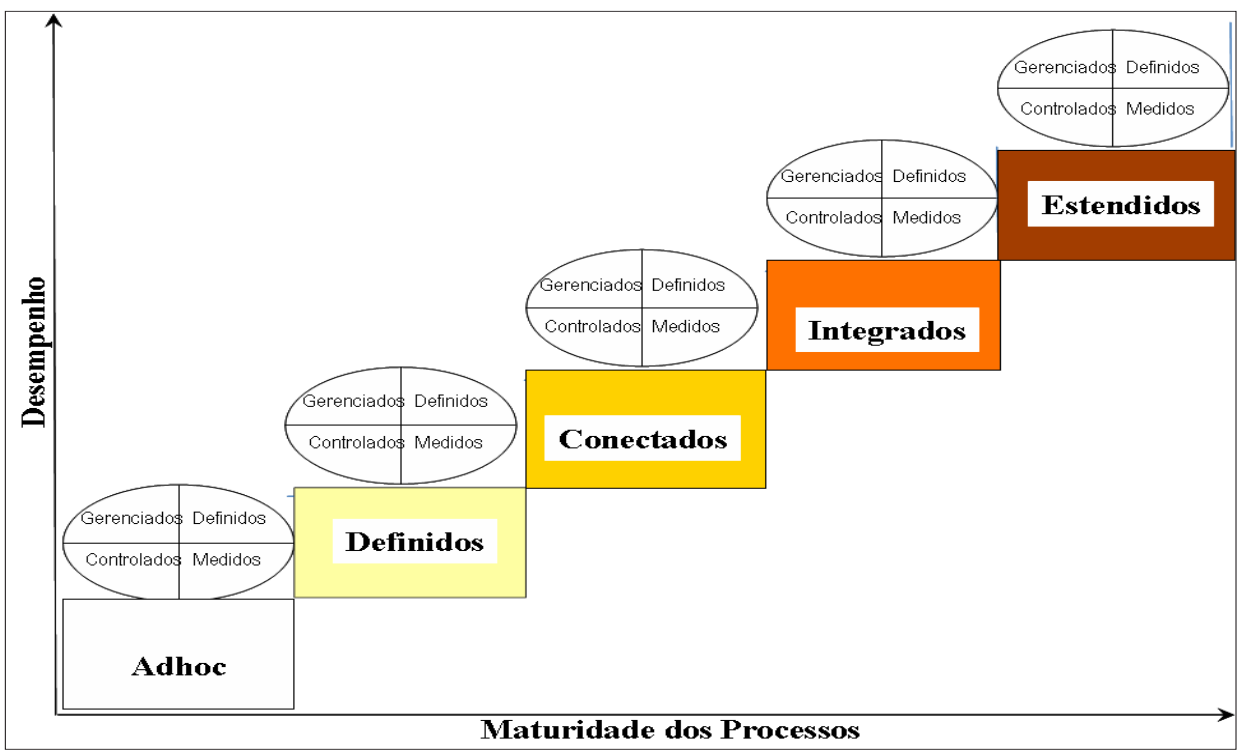

Figura 2. Ciclo de maturidade por meio da melhoria contínua.

Fonte: Elaborado pelos autores.

Inicialmente, foi definida a especificação do domínio do construto, deixando claro o que está incluso e o que está excluído dela. Em seguida, foram elaborados os indicadores, nos quais se buscou a melhor captura do construto por meio de intensa pesquisa bibliográfica. Os Quadros 4 e 5 apresentam os domínios dos construtos e os indicadores de maturidade e desempenho. 


\section{Quadro 4. Domínio dos Construtos e indicadores de maturidade}

\begin{tabular}{|c|c|}
\hline Domínio do construto & Indicadores \\
\hline $\begin{array}{l}\text { Documentação dos processos } \\
\text { Definição e documentação de um proces- } \\
\text { so de negócios (LOCKAMY; MCCORMACK, } \\
\text { 2004). }\end{array}$ & $\begin{array}{l}\mathrm{I}_{01} \text {-Definição do pessoal responsável pela monitoração e } \\
\text { controle do processo; } \\
\mathrm{I}_{02} \text {-Documentação do fluxo dos processos por meio da identifi- } \\
\text { cação das entradas e saídas de produtos; } \\
\mathrm{I}_{03} \text {-Identificação de dados de produção por meio de documen- } \\
\text { tação; } \\
\mathrm{I}_{04} \text {-Documentação do plano de gestão da propriedade; } \\
\mathrm{I}_{05} \text {-Documentação de registros/controle das operações. }\end{array}$ \\
\hline $\begin{array}{l}\text { Medição dos processos } \\
\text { Medição de aspectos do processo como } \\
\text { qualidade, tempo de ciclo, custo do } \\
\text { processo e variabilidade comparada com } \\
\text { as medidas de contabilidade tradicional } \\
\text { (MCCORMACK et al., 2003). }\end{array}$ & $\begin{array}{l}\mathrm{I}_{06} \text {-Indicadores de desempenho relacionados à produtividade; } \\
\mathrm{I}_{07} \text {-Indicadores de otimização do rendimento e eficiência } \\
\text { agrícola; } \\
\mathrm{I}_{08} \text {-Metas de desempenho de melhoria contínua; } \\
\mathrm{I}_{09} \text {-Auto avaliação dos processos em relação ao código de } \\
\text { conduta; } \\
\mathrm{I}_{10} \text {-Indicadores de controle de qualidade do processo. }\end{array}$ \\
\hline $\begin{array}{l}\text { Rastreabilidade no processo } \\
\text { "Garantia de que os produtos sustentáveis } \\
\text { certificados são originários de uma fonte } \\
\text { certificada e/ou asseguram uma produção } \\
\text { sustentável, através de um sistema de } \\
\text { identificação registrado" (UTZ CERTIFIED, } \\
\text { 2015a, p. 11). }\end{array}$ & $\begin{array}{l}\mathrm{I}_{11} \text {-A disponibilidade de informação sobre insumos; } \\
\mathrm{I}_{12} \text {-A disponibilidade de informação sobre café em pós-colheita; } \\
\mathrm{I}_{13} \text {-A disponibilidade de informação sobre café beneficiado; } \\
\mathrm{I}_{14} \text {-A capacidade de identificar o café durante o processo; } \\
\mathrm{I}_{15} \text {-A manutenção de registros para garantir a rastreabilidade. }\end{array}$ \\
\hline $\begin{array}{l}\text { BPA de Lavoura } \\
\text { "Práticas que abordam a sustentabilidade } \\
\text { ambiental, econômica e social para pro- } \\
\text { cessos na exploração agrícola e pós-pro- } \\
\text { dução que resultam em produtos agrícolas } \\
\text { seguros e de qualidade" (UTZ CERTIFIED, } \\
\text { 2015a, p. 9). }\end{array}$ & $\begin{array}{l}\mathrm{I}_{16} \text {-Os requisitos de BPA de plantio de café; } \\
\mathrm{I}_{17} \text {-Os requisitos de BPA de manutenção da propriedade } \\
\text { agrícola; } \\
\mathrm{I}_{18} \text {-Os requisitos de BPA de gestão do solo e fertilidade; } \\
\mathrm{I}_{19} \text {-Os requisitos de BPA de manejo de pragas e doenças; } \\
\mathrm{I}_{20} \text {-Os requisitos de BPA de uso de pesticidas e fertilizantes. }\end{array}$ \\
\hline $\begin{array}{l}\text { BPA de Processamento } \\
\text { "Transformação dos produtos colhidos em } \\
\text { produtos acabados ou inacabados, incluin- } \\
\text { do a alteração de produtos primários } \\
\text { (matérias) na fazenda" (UTZ CERTIFIED, } \\
\text { 2015a, p. 11). }\end{array}$ & $\begin{array}{l}\mathrm{I}_{21} \text { Os requisitos de BPA de colheita; } \\
\mathrm{I}_{22} \text {-Os requisitos de BPA de secagem de café; } \\
\mathrm{I}_{23} \text {-Os requisitos de BPA de lavagem de café; } \\
\mathrm{I}_{24} \text {-Os requisitos de BPA de armazenamento de café; } \\
\mathrm{I}_{25} \text {-Os requisitos de BPA de benefício de café. }\end{array}$ \\
\hline $\begin{array}{l}\text { Sustentabilidade do processo } \\
\text { Capacidade de satisfazer as necessidades } \\
\text { presentes com intuito de não haver } \\
\text { comprometimento das gerações futuras } \\
\text { (WCED, 1987). }\end{array}$ & $\begin{array}{l}\mathrm{I}_{26} \text {-Os requisitos de uso sustentável da água; } \\
\mathrm{I}_{27} \text {-Os requisitos de conservação ambiental relacionados à } \\
\text { proteção da natureza; } \\
\mathrm{I}_{28} \text {-Os requisitos de conservação ambiental relacionados ao uso } \\
\text { de recursos e tratamento de resíduos; } \\
\mathrm{I}_{29} \text {-Os requisitos de regulamentação trabalhista; } \\
\mathrm{I}_{30} \text {-Os requisitos de saúde e segurança do trabalhador. }\end{array}$ \\
\hline
\end{tabular}

Fonte dos indicadores: Baseado em UTZ CERTIFIED (2015a) e BRONZO et al. (2012). 
Quadro 5. Domínio dos construtos e indicadores de desempenho

\begin{tabular}{|l|l|}
\hline Domínio do construto & Indicadores \\
\hline $\begin{array}{l}\text { Desempenho Financeiro } \\
\text { Conjunto de indicadores financeiros e econôm- } \\
\text { icos de desempenho que serve de base para } \\
\text { medição da perspectiva financeira e econômica da } \\
\text { firma (KAPLAN; NORTON, 1997). }\end{array}$ & $\mathrm{D}_{01}$-Aumento de faturamento; \\
\hline $\begin{array}{l}\text { Desempenho Mercadológico } \\
\text { Conjunto de indicadores mercadológicos de }\end{array}$ & $\mathrm{D}_{03}$-Aumento do prêmio na venda de café; \\
$\begin{array}{l}\text { desempenho que serve de base para medição da da } \\
\text { perspectiva relativa aos clientes da firma (KAPLAN; } ; \\
\text { NORTON, 1997). }\end{array}$ & $\begin{array}{l}\mathrm{D}_{05} \text {-Aumento do volume comercializado; } \\
\mathrm{D}_{06} \text {-Avoluçãa da sua parcela de mercado; } \\
\text { vendido; }\end{array}$ \\
\hline
\end{tabular}

Fonte dos indicadores: Baseado em UTZ CERTIFIED (2015a) e BRONZO et al. (2012).

Neste trabalho, o construto desempenho foi avaliado por indicadores baseados no Balanced Scorecard (BSC), proposto em Kaplan e Norton (1997). As perspectivas mercadológicas e financeiras do BSC foram selecionadas em função dos objetivos precípuos deste trabalho, sendo estas as principais demandas para certificação (ampliar mercado e lucratividade). O Quadro 3 apresenta as perspectivas financeiras e mercadológica do BSC que foram escolhidas para avaliar o desempenho nesta pesquisa.

Para identificação de pontos chave de transição (turning points) foram analisados os modelos de maturidade de processos desenvolvidos por McCormack et al. (2003), bem como os de Hammer (2007) e Oliveira (2009), com o intuito de definir uma metodologia de mudança entre níveis na escala de maturidade. No modelo de maturidade proposto nesta pesquisa, os construtos são mensurados por meio do somatório dos seus respectivos indicadores, utilizando a medida estatística da mediana como ponto chave de transição. Assim, a empresa que apresentar um escore abaixo ou igual à mediana entre dois níveis na escala de maturidade será classificada no estágio inferior de maturidade destes níveis, enquanto a empresa que apresentar um escore acima da mediana entre dois níveis na escala de maturidade será classificada no estágio superior de maturidade desses níveis.

O escore total de cada firma é calculado pelo somatório dos escores obtidos dos cinco indicadores dos seis construtos ponderados pelos níveis de maturidade (Adhoc-1, Definidos-2, Conectados-3, Integrados-4, Estendidos-5 (Quadro 6). 
Quadro 6. Ponto Chave de Transição do Modelo de Maturidade de Processos

\begin{tabular}{|l|l|l|}
\hline $\begin{array}{l}\text { Nível de } \\
\text { maturidade }\end{array}$ & Escores Máximos do Modelo de Maturidade de Processos & Turning points \\
\hline Ad hoc & 6 construtos x 5 indicadores $\times 1$ ponto $=$ até 30 pontos & $\leq 45$ \\
\hline Definidos & 6 construtos $\times 5$ indicadores x 2 pontos $=$ até 60 pontos & $>45 \leq 75$ \\
\hline Conectados & 6 construtos $\times 5$ indicadores x 3 pontos $=$ até 90 pontos & $>60 \leq 105$ \\
\hline Integrados & 6 construtos $\times 5$ indicadores $\times 4$ pontos $=$ até 120 pontos & $>105 \leq 135$ \\
\hline Estendidos & 6 construtos $\times 5$ indicadores $\times 5$ pontos $=$ até 150 pontos & $>135$ \\
\hline
\end{tabular}

Fonte: Elaborado pelos autores.

A Figura 3 apresenta um exemplo de operacionalização da escala, em que a empresa hipotética está no nível de maturidade "Conectados" com um escore de 81 pontos. O escore 81 pontos está acima do ponto chave de transição 60 pontos, definido pela mediana entre os níveis "Definidos" e "Conectados", a empresa estaria, então, classificada no nível de maturidade "Conectados".

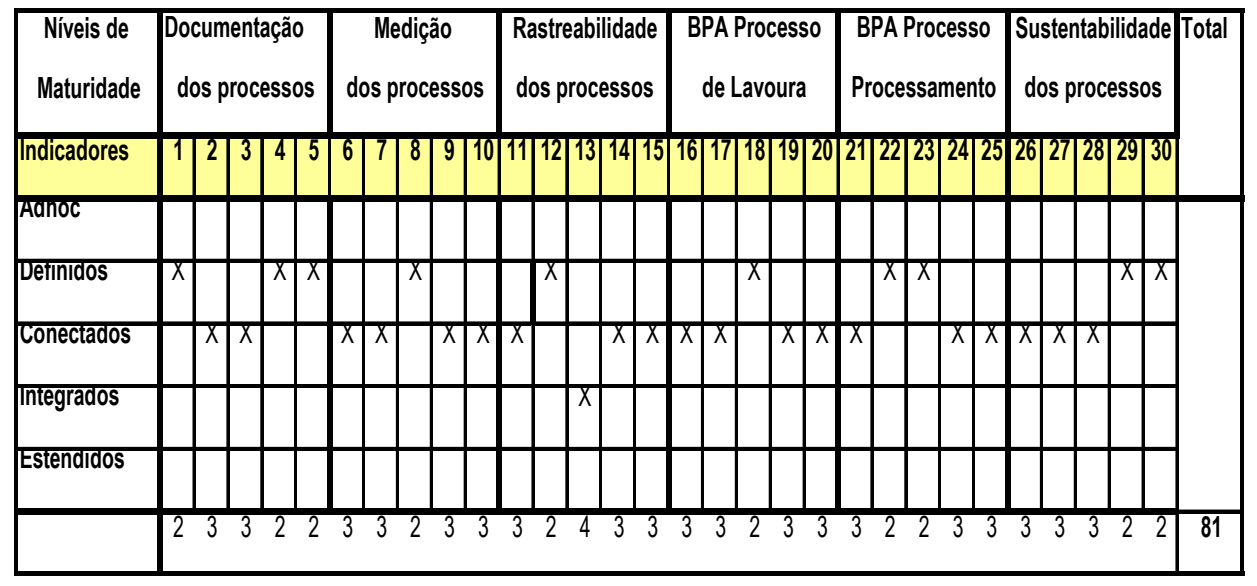

Figura 3. Exemplo de mensuração da escala

Fonte: Elaborado pelos autores. 


\subsection{VALIDAÇÃO DO MODELO DE MATURIDADE}

Após o desenvolvimento do modelo de maturidade, a validação de conteúdo foi realizada por uma equipe de três especialistas em gestão de processos e três especialistas em cafeicultura durante os sete primeiros meses de 2015. Após esta etapa, o modelo de maturidade e o questionário foram analisados em uma seção de grupo focal. Foi demonstrado ao grupo focal os seus diversos usos: instrumento descritivo; instrumento prescritivo; instrumento comparativo. Os participantes do grupo focal compreenderam a possibilidade de definição de estratégias individuais para produtores, bem como as possíveis estratégias coletivas.

A pertinência da escolha dos seis atributos do modelo de maturidade foi perguntada aos especialistas e ao grupo focal. Para os especialistas, os seis atributos foram capazes de sintetizar os fatores essenciais para a certificação de processos na cafeicultura pela perspectiva da UTZ Certified. Esta percepção, também, foi reforçada pelo grupo focal.

Foi questionada, também, a pertinência da escolha dos cinco indicadores dos seis atributos do modelo de maturidade tanto aos especialistas quanto aos participantes do grupo focal. É importante destacar que cada indicador do questionário que se encontra no código de conduta da UTZ Certified foi analisado pelos especialistas e visto e analisada no grupo focal. Segundo a opinião dos especialistas, estes indicadores foram suficientes na contemplação dos requisitos deste código de conduta. Esta percepção, também, foi reforçada pelo grupo focal.

A apresentação do modelo de maturidade suscitou um debate interessante no grupo focal sobre a possibilidade de uso comparativo dos escores médios de grupos específicos determinados por fatores comuns na definição de políticas adotadas pelas cooperativas e associações, como, por exemplo, volume de produção, tempo de certificação, nível de maturidade. A possibilidade de usar outras medidas estatísticas de dispersão e gráficos para verificar a dispersão dos produtores em relação à média foi apresentado ao grupo, que visualizou como sendo uma possibilidade rica para a definição destas políticas. 


\subsubsection{Construto Maturidade}

O construto "Maturidade" foi elaborado a partir de Lockamy e McCormack (2004), e é a base sobre a qual foi elaborado o modelo de maturidade e o método do ciclo de maturidade proposto neste trabalho (Figura 4). O especialista 2 colaborou na revisão do modelo de maturidade ao ressaltar a importância da especificação do domínio do construto, deixando claro o que está incluso e o que está excluído dela. $\mathrm{O}$ especialista 1 analisou e validou os indicadores que capturam o construto, bem como a escala proposta. Ambos validaram a proposta de pontos chaves de transição, que é uma questão fundamental para determinação da mudança das firmas entre os estágios de maturidade.

$\mathrm{Na}$ escolha do método de pontos chave de transição (turning points) foram analisados junto com o especialista 1 os métodos de McCormack et al. (2003), Hammer (2007) e Oliveira (2009). Como uma evolução destes métodos, optou-se por usar um novo método (Quadro 6), o qual tanto os especialistas quanto o grupo focal compreenderam claramente.

Com relação à construção da escala, inicialmente, por indicação dos especialistas 1 e 2, pensava-se em trabalhar com a derivação da escala proposta por McCormack et al. (2003), baseando-se no escopo de pesquisa da díade. No entanto, após a análise da percepção do entrevistado 1 e dos especialistas 4 e 5 foi possível perceber que a opção da díade não seria aplicável ao contexto pesquisado, optando então por processos internos apenas.

No grupo focal, foi questionado pelos participantes o porquê da escolha da UTZ Certified como opção de certificação. Inicialmente, o grupo sugeriu o uso também da certificação Rainforest Alliance em virtude da mesma estar proporcionando um prêmio mais significativo do que o provido pela UTZ Certified. Foi informado que a escolha da UTZ Certified se deu pelo seu conceito de evolução em estágios de maturidade, que permite que as melhores práticas sejam objetivadas em uma filosofia de melhoria contínua. Entendendo a proposta, os participantes do grupo focal aprovaram a escolha, concordando que realmente a essência da UTZ Certified é a filosofia de melhoria contínua dos processos, o que vai ao encontro da proposta de maturidade definida neste trabalho. 
A concepção de ciclo de maturidade por meio da melhoria contínua, apresentada na Figura 4, foi aprovada por unanimidade pelos participantes do grupo focal. Esta concepção foi objetivada nos indicadores do questionário, nos quais os processos precisam ser necessariamente definidos, medidos, controlados e gerenciados. Todos os componentes do grupo focal concordaram que o produtor em um estágio de maior maturidade deve utilizar a certificação para fins de gestão, com intuito estratégico.

\subsubsection{Construtos que Constituem o Construto Maturidade}

Os indicadores dos Construtos "Documentação do Processo", "Medição dos Processos", "Rastreabilidade no Processo", "BPA do Processo de Lavoura", "BPA do Processo de Processamento" e "Sustentabilidade dos Processos" foram compilados de Bronzo et al. (2012) e UTZ Certified (2015). Foi percebido por meio da reunião do grupo focal que os produtores não tiveram dificuldades em compreender as questões relacionadas a estes Construtos, pois todos afirmaram que as questões estão objetivas e relacionadas ao cotidiano da certificação de suas firmas.

Para o especialista 4, foi sugerido que a questão "documentação de dados de produção" precisa ser mais detalhada, explicitando os itens que compõem este indicador, como os mapas, a área de produção e a estimativa de produção.

Houve consenso no grupo focal sobre a percepção de que a documentação de processo e a padronização aliada à medição de processos colaboram para melhoria da gestão e, em consequência, na redução de custos pela redução de desperdícios. O aumento das vendas de cafés especiais também foi consensual, pois, na visão do grupo, a certificação tende a aumentar a qualidade do produto.

Os componentes do grupo focal foram estimulados a se posicionarem a respeito da importância da medição de processo. De acordo com a percepção do grupo, foi possível perceber que embora haja vários registros e indicadores, ainda é preciso conseguir usar a riqueza de dados para a tomada de decisão estratégica. Com relação a este construto, o especialista 4 recomendou que fosse utilizado no final da questão "a auto avaliação dos processos em relação ao código de conduta", o nome da certificação selecionada. O entrevistado 6 sugeriu que o termo UTZ Kapeb fosse substituído por UTZ Certified nas questões deste construto. 
O entrevistado 3 sugeriu que as questões relacionadas a disponibilidade de informação sobre insumos, produtos em processo e produtos acabados fossem adequadas ao setor ficando a disponibilidade de informações sobre insumos, café em pós-colheita, e café beneficiado.

O entrevistado 3 sugeriu que a questão sobre boas práticas agrícolas de material de plantio fosse substituída por boas práticas agrícolas de plantio de café. $\mathrm{O}$ entrevistado 3, também, sugeriu que para facilitar o entendimento do questionário fosse colocado em parênteses exemplos que detalhassem os requisitos. Esta sugestão foi reforçada pelo especialista 4. Com base nestas sugestões, os termos análise de folha, análise de solo, Manejo Integrado de Pragas (MIP) e Equipamento de Proteção Individual (EPI) foram incorporados ao questionário.

Com relação a este construto, o especialista 4 recomendou que fosse utilizado no final de cada questão o nome da certificação selecionada. Na mesma linha de raciocínio, o entrevistado 6 sugeriu que as questões sobre BPA de lavoura tivessem o termo UTZ Kapeb substituído por UTZ Certified. Tanto o especialista 4 quanto o entrevistado 3 sugeriram que as questões relacionadas a este construto especificassem entre parênteses do que se trata cada indicador quando houvesse possibilidade de dúvida.

No caso do armazenamento, o entrevistado 3 recomendou que se utilizasse o termo "tulhas" para que o produtor não confundisse com o armazenamento que é realizado nas cooperativas, ficando claro que a questão aborda é o armazenamento na propriedade agrícola. No caso de beneficiamento do café, o entrevistado 3 recomendou que se utilizasse o termo benefício ao invés de controle de qualidade no beneficiamento, para que o produtor não o confundisse com o controle de qualidade de outras etapas. Com relação a este construto, o especialista 4 recomendou que fosse utilizado ao final de cada questão o nome da certificação selecionada. O entrevistado 6 sugeriu que as questões sobre BPA do processo de processamento tivessem o termo UTZ Kapeh substituído por UTZ Certified.

Os componentes do grupo focal foram estimulados a se posicionarem a respeito da diferença entre os indicadores da UTZ Certified em relação a outras certificações, tais como a Rainforest Alliance, sendo possível perceber que há pouca diferença entre ambas as certificações. Esse fato foi também destacado pelo 
entrevistado 3, ao destacar a diferença de enfoque entre as duas certificações: uma mais orientada para segurança alimentar e a outra para a preservação ambiental, embora tenham em comum o conceito de produção sustentável.

Tanto o especialista 4 quanto o entrevistado 3 sugeriram que as questões relacionadas a sustentabilidade dos processos fossem mais detalhadas. $\mathrm{O}$ entrevistado 3 sugeriu que incluísse os termos "fauna e flora" à questão que abordava os requisitos relacionados à proteção da natureza. $\mathrm{O}$ especialista 4 recomendou que fosse utilizado no final de cada questão o nome da certificação selecionada. $\mathrm{O}$ entrevistado 6 sugeriu que as questões sobre Sustentabilidade tivessem o termo UTZ Kapeb substituído por UTZ Certified.

\subsubsection{Construtos Desempenho Financeiro e Desempenho Mercadológico}

Os indicadores dos Construtos Desempenho Financeiro e Desempenho Mercadológico foram baseados no BSC, sendo compilados de Bronzo et al. (2012). Embora o BSC tenha quatro perspectivas, as perspectivas mercadológicas e financeiras do BSC foram selecionadas pois representam as principais metas dos produtores ao buscarem a certificação: a ampliação de mercados e a lucratividade. É percepção dos participantes do grupo focal de que estas duas dimensões são as fundamentais para a competitividade no seu setor.

No construto desempenho financeiro, inicialmente foram desenvolvidos dois indicadores baseados em rentabilidade e redução de custos. De acordo com a opinião do especialista 6 , foram incorporados mais dois indicadores relacionados a rentabilidade e a faturamento. Na opinião do entrevistado 4 , um fator que diferencia os produtores certificados da região é o fato que são empresários com foco em negócios e não aquele produtor tradicionalista de outras regiões brasileiras.

Segundo a opinião do especialista 3, a obtenção do prêmio da certificação UTZ Certified está reduzido se comparado com a Rainforest Alliance. Foi pontuado pelos participantes do grupo focal que o viés para baixo do prêmio alcançado pelo produto UTZ Certified tem compensado quando o produtor tem outras certificações como Nespresso e o Rainforest Alliance. Esse problema foi levantado, também, pelo especialista 4. Evidência dessa diferença foi observada na percepção do entrevistado 
3, ao mencionar a parceria com a Nespresso. Um exemplo dado na reunião do grupo focal foi o fato dos produtores obterem um duplo prêmio pelas duas certificações (certificado Nespresso e Rainforest Alliance). Realmente, após pesquisa no site da Nespresso, foi percebido que o preço pago por café certificado Nespresso está 30\% a $40 \%$ acima do preço do café tradicional.

Tanto na opinião dos especialistas em cafeicultura quanto na interpretação dada pelos participantes do grupo focal, o tempo padrão de três anos que foi definido para todos os indicadores mercadológicos e financeiros são adequados em virtude do tempo médio de certificação dos produtores do cerrado mineiro.

\subsubsection{Construtos de Moderação}

Os indicadores dos Construtos de Moderação foram definidos para analisar o efeito moderador de alguns indicadores. A escala relacionada ao tempo de obtenção da certificação foi aprovada por todos os especialistas em cafeicultura, sem que houvesse objeção. O mesmo sentimento foi citado na reunião com o grupo focal. Para os produtores que participaram do grupo focal, o tempo de obtenção da sua certificação ficou entre "três a quatro anos", o que pode confirmar o tempo padrão para avaliar o desempenho.

Foi relatado pelos participantes do grupo focal que a maioria dos produtores que obtiveram a UTZ Certified tem também o certificado da Rainforest Alliance, visto que na opinião do grupo os requisitos são semelhantes, que também foi confirmado pelo entrevistado 3. O participante do Grupo Focal 1 e o participante do Grupo Focal 2, além do certificado UTZ Certified, possui também a certificação da Rainforest Alliance e o Certifica Minas. O que os diferencia seria a obtenção do certificado Starbucks pelo primeiro, e a obtenção do certificado Nespresso, para o segundo. Já o entrevistado do Grupo Focal 3 obteve a certificação Global Gap, além da UTZ Certified.

Com relação à questão da produção média em sacas de café por ano, o entrevistado 4 sugeriu o aumento das opções de resposta, propondo as seguintes formas: até 1500 sacas de café; entre 1500 e 5000 sacas de café; entre 5000 e 10000 sacas de café; entre 10000 e 15000 sacas de café; acima de 15000 sacas de café. No grupo focal, todos os produtores se enquadraram no perfil definido "entre $5000 \mathrm{e}$ 10000 sacas de café". 


\subsection{MÉTODO DO CICLO DE MATURIDADE PARA O SAG DE CAFÉ}

Neste item, será apresentado o Método do Ciclo de Maturidade para o SAG de Café (Figura 4), que foi projetado para ser implantado em um grupo estratégico composto por firmas homogêneas do SAG de café, formado por produtores, fornecedores, indústrias, varejistas. A organização pesquisadora responsável por aplicar o método pode ser uma federação, associação, cooperativa, consultoria, agente governamental, indústria, entre outras.

Na etapa 1, a organização pesquisadora precisa definir o escopo de análise da implantação do modelo de maturidade. Neste momento, deve ser definida a abrangência da pesquisa, que poderá ser interna, por díade ou externa. $\mathrm{Na}$ perspectiva interna, serão analisados apenas os processos intraorganizacionais. Pela perspectiva da díade, além dos processos intraorganizacionais a pesquisa abrangerá, também, os processos que envolvem fornecedores e compradores imediatos. Já na visão externa, o escopo de análise abarcará os processos de toda a cadeia produtiva, ou seja, do fornecedor inicial ao consumidor final.

Na etapa 2, será necessário selecionar qual certificação deverá ser utilizada para servir de base para construção dos indicadores e, por conseguinte, das questões do instrumento de pesquisa (questionário). Nesta fase, será necessário ajustar o instrumento de pesquisa alterando e incorporando indicadores complementares, necessários em função do escopo escolhido e em virtude da certificação selecionada. Estes ajustes deverão ser validados por especialistas, integrantes da organização pesquisadora e por um grupo de produtores que já implantaram a certificação.

Na etapa 3, deverá ser realizada a coleta e análise de dados. Para tanto, deverá ser selecionada uma amostra para a realização da coleta de dados. Inicialmente, precisará ser escolhido o tipo de amostragem probabilística, que poderá ser aleatória simples, sistemática, estratificada ou por conglomerados. Se o número de firmas a serem pesquisadas for pequeno poderá ser utilizado o censo. Os dados deverão ser, então, coletados desta amostra e em seguida analisados por estatística descritiva e ou multivariada.

A etapa 4 compreende a apresentação dos resultados da pesquisa aos representantes das firmas. Nesta fase, cada firma poderá receber o escore obtido em 
cada indicador e o comparativo em relação à média das outras firmas da amostra, o que possibilitará aos gestores reconhecer os pontos críticos que precisam ser melhorados para a evolução no modelo de maturidade. Também poderá ser fornecido o escore total que permitirá reconhecer o nível de maturidade alcançado, bem como a comparação com a média das demais firmas da amostra.

Em relação aos resultados derivados do desenvolvimento e da aplicação deste modelo de maturidade, é possível observar contribuições gerenciais potenciais e importantes a serem alcançadas a partir da disponibilização, por exemplo, de alguns produtos: relatórios sucintos com os principais resultados dos levantamentos (sumários executivos); representação visual do posicionamento da firma no modelo de maturidade (gráfico de radar); relatórios individuais sumarizados, que de forma padronizada identificará o desempenho da firma em relação à média dos resultados dos demais participantes da pesquisa e também um guia (roadmap) para orientar esforços por melhores resultados de desempenho das operações.

$\mathrm{Na}$ etapa 5, os especialistas, em virtude dos pontos críticos, sugerem recomendações para a melhoria dos processos, permitindo a priorização de esforços e recursos pela firma. Na etapa 6 , a organização pesquisadora deve orientar o processo de implantação das recomendações, bem como realizar o acompanhamento de sua implementação, visando o controle. Por fim, a organização irá se preparar para recomeçar o ciclo de maturidade. 


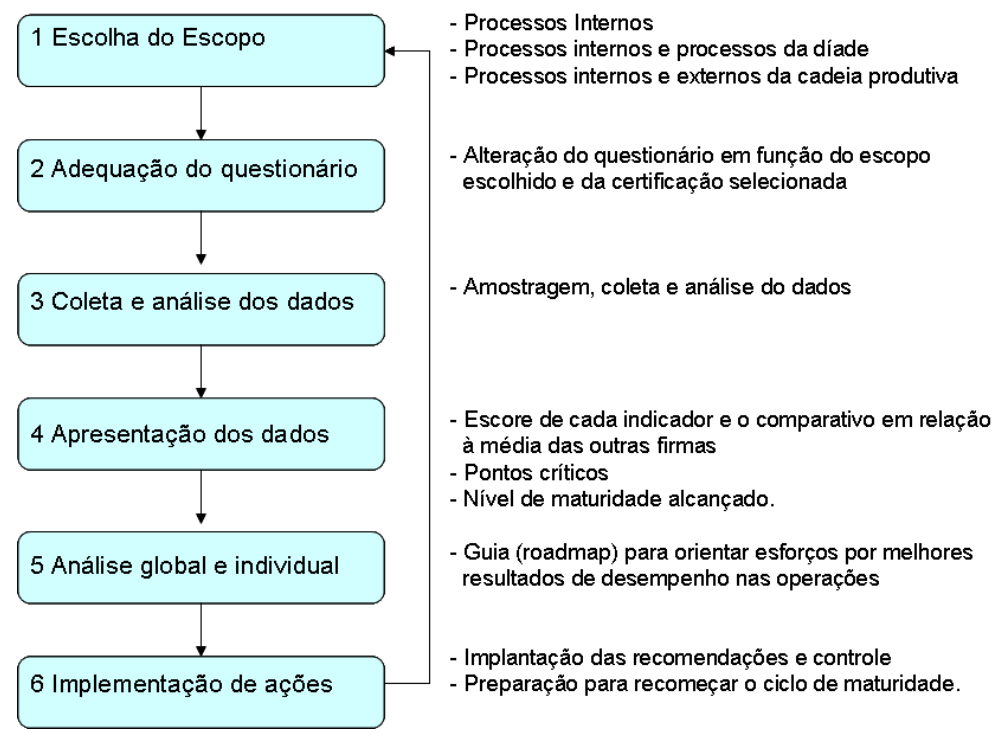

Figura 4. Método do Ciclo de Maturidade para o SAG de Café

Fonte: Elaborado pelos autores.

\section{CONSIDERAÇÕES FINAIS}

É possível depreender do estudo construído nas seções precedentes que este modelo abarca de forma satisfatória a certificação escolhida. A principal contribuição deste trabalho é a proposição e validação de conteúdo do modelo de maturidade, que permitirá avaliar em pesquisas empíricas futuras a maturidade dos processos das firmas certificadas. Possibilitará, ainda, validar a relação do impacto da maturidade de processos certificados sobre o desempenho das empresas do segmento agroindustrial do café, bem como em outros sistemas agroindustriais.

Este modelo de maturidade permitirá verificar se a certificação tem a capacidade de levar as firmas a percorrerem processos evolutivos, verificado pela maturação e pelo desempenho das firmas no tempo. Há necessidade de tal investigação. Podem existir situações em que a certificação, per si, não seja capaz de promover a maturidade das empresas certificadas? Ou, ainda, a certificação não seja capaz de promover maior desempenho? A definição de questões como essas são importantes para o campo de estudos de certificação. 
A contribuição deste trabalho para o agronegócio está focada no modelo de maturidade criado. A utilização do modelo como uma ferramenta gerencial pode ter repercussão positiva no incremento da competitividade da agroindústria, que é um setor econômico relevante no país, aumentando a competitividade interna das empresas e seu potencial de competitividade também nas exportações.

Algumas questões são apresentadas visando trabalhos futuros em SAG's: verificar se os processos mais homogêneos facilitam criar um roadmap específico para cada empresa; validar a maturidade dos processos das firmas certificadas e o impacto da maturidade no desempenho mercadológico e financeiro; analisar os custos de implantação de um modelo de maturidade nestes sistemas produtivos.

Embora se ressalte a relevância dos construtos propostos tanto em relação às práticas empresariais contemporâneas quanto também com relação à perspectiva teórica-conceitual sobre o tema, há que se destacar aqui as limitações características de um estudo exploratório. Convém salientar a necessidade de complementação deste trabalho por meio de estudos conclusivos de natureza quantitativa. Sob tal aspecto, a comprovação da validação do modelo proposto neste trabalho perpassa pela realização de estudos mais abrangentes que permitam comprovar as proposições apresentadas.

Por fim, entende-se que o modelo de maturidade desenvolvido e o método do ciclo de maturidade proposto podem assumir força convergente e proporcionar uma complementaridade teórica capaz de gerar uma visão mais abrangente e impulsionar o desenvolvimento de novas teorias e mais robustos modelos de maturidade, necessários à compreensão das práticas e estratégias de diferentes organizações que, hoje, participam de SAG's.

\section{REFERÊNCIAS}

BRONZO, M. L.; RESENDE, P. T. V.; OLIVEIRA, M. P. V.; MCCORMACK, K.; SOUSA, P. R.; FERREIRA, R. L. Gestão de processos, indicadores analíticos e impactos sobre o desempenho competitivo em grandes e médias empresas brasileiras dos setores da indústria e de serviços. Gestão \& Produção (UFSCAR. Impresso). v. 19, p. 389$404,2012$. 
CONSELHO DOS EXPORTADORES DE CAFÉ. Exportações brasileiras de café. 2014. Disponível em: < http://www.cecafe.com.br/> . Acesso em: 01 set. 2015.

CROSBY, P. B. Quality is free: the art of making quality certain. Nova York: McGraw-Hill Companies, 1979.

HAMMER, M. The process audit. Harvard Business Review, Abril, 2007, p. 111-123.

INFORME ESTATÍSTICO DO CAFÉ. Estatísticas. Disponível em: <http://www.agricultura.gov.br/vegetal/estatisticas > . Acesso em: 01 set. 2015.

KAPLAN, R. S.; NORTON, D. P. A estratégia em ação: balanced scorecard. 4. ed. Rio de Janeiro: Campus, 1997.

LAHTI, M.; SHAMSUZZOHA, A. H. M.; HELO, P. Developing a maturity model for Supply Chain Management. International Journal of Logistics Systems and Management, v. 5, n. 6, p. 654-678, 2009.

LEME, P. H. M. V. A construção do mercado de cafés certificados e sustentáveis da UTZ Certified no Brasil: As práticas e os arranjos de mercado. 2015. 274 p. Tese (Tese em Administração) - Universidade Federal de Lavras, Lavras.

LOCKAMY, A.; MCCORMACK, K. The development of a supply chain management process maturity model using the concepts of business process orientation. Supply Chain Management: An International Journal, v. 9, n. 4, 2004, p. 272-278.

MCCORMACK, K.; BRONZO, M.; OLIVEIRA, M. P. V. Supply Chain Maturity and Performance in Brazil. Supply Chain Management: An International Journal, v. 13, n. 4, p. 272-282, 2008.

MCCORMACK, K.; JOHNSON, W,; WALKER, W. Supply Chain Networks and Business Process Orientation: Advanced Strategies and Best Pratices. APICS series on resource management. CRC Press LLC. Boca Raton, Florida, 2003.

OLIVEIRA, M. P. Modelo de maturidade de processos em cadeias de suprimentos: precedências e os pontos-chave de transição. 2009. Tese (Doutorado em Administração) - Universidade Federal de Minas Gerais, Belo Horizonte.

OLIVEIRA, M. P. V.; BRONZO, M.; McCORMACK, K. The supply chain process ma- 
nagement maturity model - SCPM3. In: ONKAL, D. (Org). Supply Chain Management: Pathways for Research and Practice. August, 2011, p. 201-218.

POTTS, J. et al. The State of sustainability initiatives review 2014: standards and the green economy. London: International Institute for Sustainable Development, 2014. 254 p.

UTZ CERTIFIED. Código de conduta núcleo. Versão 1.1. Amsterdam. 2015a.

UTZ CERTIFIED. Effects of UTZ certification according to coffee farmers in Brazil. São Paulo. 2015b.

WORLD COMISSION ON ENVIROMENTAL AND DEVELOPMENT (WCED). Our common future. Oxford: Oxford University Press, 1987.

Recebido em: 24/01/2016 Aceito em: 06/11/2017 